\title{
Comparison of four species diversity indices in mangrove community
}

\author{
HANJAR MULYA ${ }^{1, \bullet}$, YANTO SANTOSA ${ }^{2}$, IWAN HILWAN ${ }^{3}$ \\ ${ }^{1}$ Program of Tropical Biodiversity Conservation, Graduate School. Institut Pertanian Bogor. Jl. Raya Dramaga, Kampus IPB Dramaga, Bogor 16680, \\ West Java, Indonesia \\ ${ }^{2}$ Department of Forest Resources Conservation and Ecotourism, Faculty of Forestry and Environment, Institut Pertanian Bogor. J1. Ulin Lingkar \\ Akademik, Kampus IPB Dramaga, Bogor 16680, West Java, Indonesia \\ ${ }^{3}$ Department of Silviculture, Faculty of Forestry and Environment, Institut Pertanian Bogor. Jl. Ulin Lingkar Akademik, Kampus IPB Dramaga, Bogor \\ 16680, West Java, Indonesia. Tel.: +62-251-8621677, `email: anjarmulya @gmail.com
}

Manuscript received: 31 May 2021. Revision accepted: 11 August 2021.

\begin{abstract}
Mulya H, Santosa Y, Hilwan I. 2021. Comparison of four species diversity indices in mangrove community. Biodiversitas 22: 3648-3655. Mangrove communities have a tidal environment that affects their species composition, which may be finite but the abundance may vary between species individuals. Many ecologists have used indices to measure species diversity without knowing the best suitable index for the community and its statistical characteristics. Therefore, this study aimed to compare species diversity indices in mangrove communities to obtain the best and most appropriate index for mangrove diversity. The comparison was done using the Simpson (1-D), Shannon, Menhinick, and Margalef indices, which were widely used and considered the best measures in various communities. The data was obtained from the field sampling using a single plot of $80 \times 40 \mathrm{~m}^{2}$, and then it was simulated to obtain standardized variables so that the indices got the same treatment. It was calculated with descriptive statistics and species diversity indices among other Simpson, Margalef, Shannon, and Menhinick indices. Pearson correlation and UPGMA cluster were used to get conformity based on the best index criteria. The results showed the Margalef index was the best in performance that passed the assessment criteria more than Simpson (1-D), Shannon, and Menhinick index. It had a low correlation with sample variance and normality marker but had high variability of the index value. It was also sensitive to the number of species, good reduced individual sample, and good correlation with similar indices. Thus, we concluded that the Margalef index was the best index for mangrove community diversity measurement. The index was recommended for monitoring and evaluating the species diversity assessment for the mangrove community. It should not use several species diversity indices with similar meanings.
\end{abstract}

Keywords: Mangrove, Margalef index, Menhinick index, Shannon index, Simpson index, best index

\section{INTRODUCTION}

Species diversity measurement is necessary to monitor and evaluate biodiversity conservation (Moris et al. 2014) and to get quantitative estimates of biological variability as entities of a community (Chiarucci et al. 2011). Species is the most appropriate level of measurement because it's a container for genetic and characteristics of a community. Species diversity measurement describes species richness taken as the number of individuals of total or proportion (evenness) in the communities (Granger et al. 2015) and widely applied in the ecology from the last few decades (Semeniuk and Cresswell 2013). Species diversity is quantified by constructing mathematical functions generally (Daly et al. 2018) known as species diversity indices. There are many statistical properties relating to species composition and species-numbers relations, and each may provide a different perspective of the communities (Magurran 2004). However, different communities have different numbers of species and individuals, so the diversity indices must be flexibly applied to different communities (Kumar et al. 2021). If not, it can provide contradictory results leading to misleading or incorrect conclusions about a community's diversity (Daly et al. 2018).

A diversity measure must be applied to any community independently of the species-abundance, its non-parametric measure (Hubalek 2000). Lately, not a single diversity indices have applied to all types of communities (Granger et al. 2015), which was evident with a simple comparison between indices in the same community (Semeniuk and Cresswell 2013). The concept of diversity is often confused with the results of various indices measuring it (Evangelista et al. 2012; Daly et al. 2018) because it is considered to have different advantages and disadvantages (Magurran 2004). The quality and sensitivity of indices are still debated and superiority of one particular index is unclear and has not been established (Palaghianu 2014). In indices commonly used in different types of communities, Simpson (1-D), Shannon, and Menhinick Indices are the best index in the communities of birds (Jintun 1999; Hubalek 2000; Goudarzian and Evanirfad 2017; Tinio and Sebual 2021) and invertebrates (Mirzaie et al. 2013; Shah and Pandit 2013; Moris et al. 2014), while Margalef index is the best index in low and high land and lower mountain plant communities (Yeom and Kim 2011; Kanieski et al. 2018). Each index has a varied sensitivity to the number of species and individuals (Magurran 2004) or their descriptive statistics (Heip and Engels 1974; Hubalek 2000) so that it has a different effect in each community (Moris et al. 2014; Daly 2018). The difference in the index indicates that community differences can produce the different best indices, one of which may occur in the mangrove 
community. This community has a structure of mangroves that's generally straightforward, and the number of species is limited but may be very abundant for their individuals with tidal characteristics. This may be due to environmental variables for specific species composition (Pandita et al. 2019).

Certainly, this correlates with the value of diversity indices such as Margalef, Menhinick, Simpson (1-D), and Shannon indices which used those variables, so those indices vary. Identities of species diversity indices with the variables can determinant the best index in particular communities (Hubalek 2000). Thus, this study aimed to compare Simpson (1-D), Shannon, Menhinick, and Shannon indices as species diversity indices in the mangrove community to find out the best index for this community. It can be used for quantitative characterization of mangrove vegetation structure and dynamics, which is required to assess coastal habitat vulnerability (NfotabongAtheull et al. 2013).

\section{MATERIALS AND METHODS}

\section{Study area}

This study was conducted in Biawak Island Marine Management Area, Indramayu, Indonesia (Figure 1).
Biawak Island is a cluster of small islands where the land is dominated by a good and natural stand of mangrove species in the community. A survey was conducted in December 2019.

\section{Procedures}

Data used as variables of species diversity indices were the number of species and the number of individuals of mangrove plants. The data was carried out from field sampling that a single rectangle plot with a size of $80 \times 40$ meters covering an area of $3,200 \mathrm{~m}^{2}$. First, the vegetation species were identified as true mangrove groups. It was chosen because the species were truly found in intertidal environmental conditions which connects terrestrial and marine biota so that the boundaries of the community observed can be identified with certainty. Then, field sampling data were simulated to standardize the number of species and the number of individuals. The scheme simulation follows: Increases three rare species from the total number of species (i), decreases three rare species from the total number of species (ii), increases 100 individuals from dominant species (iii), and decreases 100 individuals from dominant species (iv). It was to find out the index response to an equivalent number of variables.

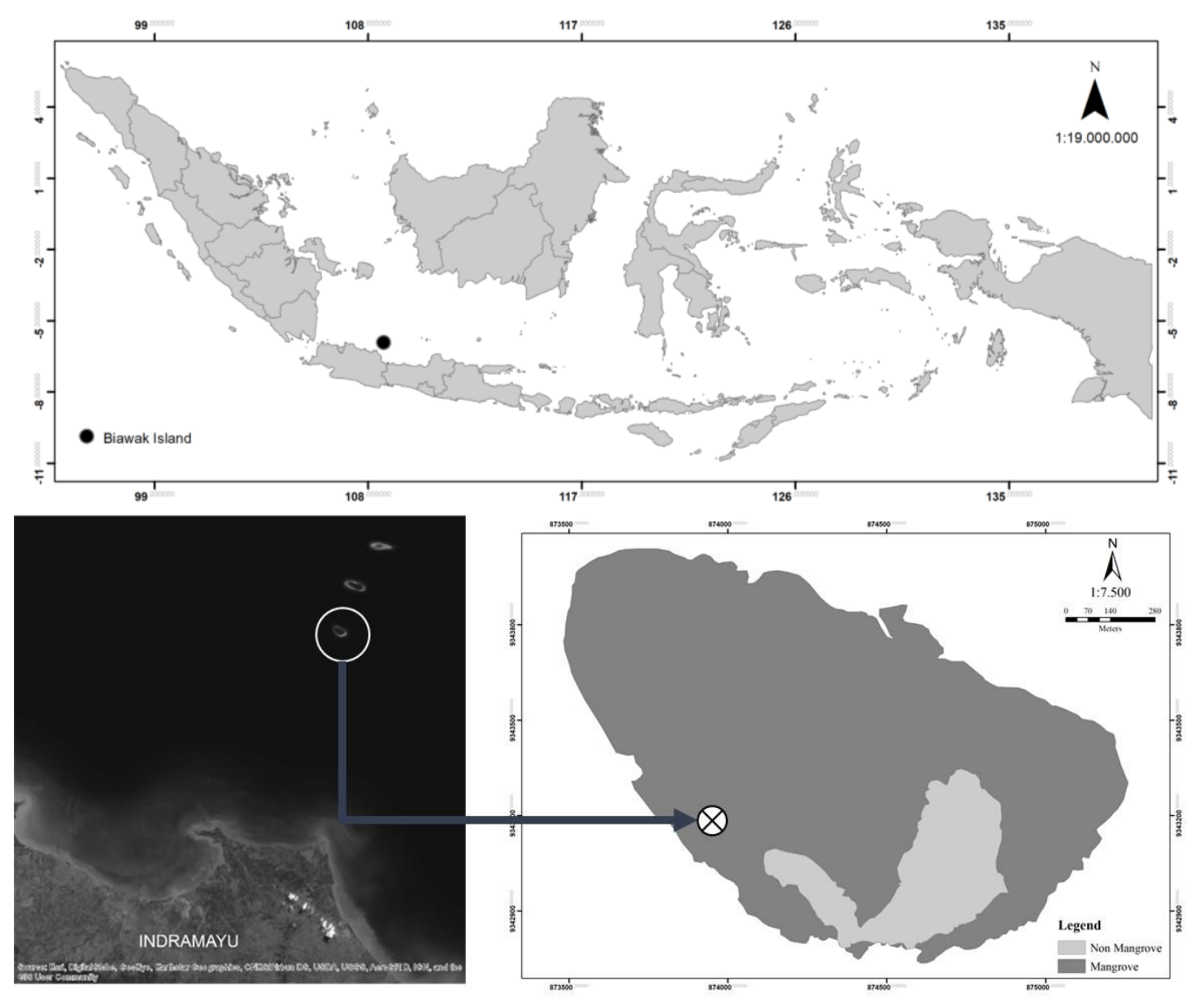

Figure 1. Map of study area in Biawak Island Marine Management Area, Indramayu, Indonesia 


\section{Data analysis}

Data were calculated with descriptive statistics and species diversity indices among others Margalef index (Margalef 1958), Menhinick index (Menhinick 1964), Shannon index (Shannon and Weaver 1949), and Simpson (1-D) index (Simpson 1949). Those indices were the best measure across communities and were widely used. Their formulas are as follows:

$$
\text { Margalef Index }\left(\mathrm{D}_{\mathrm{mg}}\right): D_{m g}=\frac{S-1}{\ln (N)}
$$

Menhinick Index $\left(\mathrm{D}_{\mathrm{mn}}\right): D_{m n}=\frac{S}{\sqrt{N}}$

Shannon index $\left(\mathrm{H}^{\prime}\right): \mathrm{H}^{s}=-\sum_{\mathrm{i}=1}^{s}\left[\frac{n_{\mathrm{i}}}{\mathrm{N}} \ln \frac{n_{\mathrm{i}}}{\mathrm{N}}\right]$

Simpson index (1-D): ${ }^{1-\mathrm{D}=} \sum_{\mathrm{i}=1}^{\mathrm{s}} p_{i}{ }^{2}$

Where,

$S$ : the total number of species in a sample/community

$n_{i}$ : the number of individuals of the $i$-th species, where $i$ $=1,2, \ldots, S$

$N$ : the total number of individuals in a sample/community: $N=\sum$

$p_{i}$ : the proportion of the $i$-th species (frequency or relative abundance, $\left.n_{\mathrm{i}} / N\right)$; the relative abundance represents, in fact, dominance of a species $\left(D_{\mathrm{i}}=100 \cdot p_{i}\right)$. Obviously, $\Sigma p_{i}=1$.

Comparison of species diversity indices was analyzed using Pearson correlation and cluster analysis with correlation coefficient and UPGMA that was performed using PAST 4.03. Determination of the best index based on the most passes of the criteria assessment follows: (i) the species diversity indices should be a low correlation with variance and coefficient of sample variation (Heip and Engels 1974; Hubalek 2000), (ii) low correlation with normality markers such as skewness and kurtosis (Heip and Engels 1974; Hubalek 2000), (iii) moderate or high correlation with the number of species (Hubalek 2000), (iv) low correlation with the number of individuals (Hubalek 2000), (v) sensitive to the number of species at an equal number of individuals (Margalef 1958; Menhinick 1964; Hubalek 2000; Magurran 2004), (vi) insensitive to the number of individuals at an equal number of species (Hubalek 2000; Magurran 2004), and (vii) good correlation with similar species diversity indices (Hubalek 2000).

\section{RESULTS AND DISCUSSION}

Comparison of four species diversity indices used descriptive statistics, sensitivity of species diversity indices, and assessment criteria of the best species diversity indices based on their correlations.

\section{Descriptive statistics and species diversity indices}

The number of species ranged between $8-14$ with mean of 11 and the number of individuals varied between 401 - 601, the mean being 501 individuals. From the analysis, the Simpson index ranged between $0.59-0.74$ with mean of 0.66 , Shannon index ranged between 1.33 1.68 with mean of 1.49 , Menhinick index varied between $0.36-0.63$ with mean of 0.49 , and Margalef index ranged between $1.12-2.10$ with mean of 1.61 . The small variance showed by the number of species (S) simulation and the high variance showed by the number of individuals $(\mathrm{N})$ simulation. Nevertheless, all samples were not normal in their distribution as evident from skewness and kurtosis values (Table 1)

\section{Sensitivity of species diversity indices}

The diversity indices were using the number of species and the number of individuals as variables of measurement. Therefore, it should be sensitive to numerical changes. The Margalef index showed a significant numerical change from decreased three species to increased three species from field sampling data as 1.13 to 2.09 or consistently increased 0.48. It didn't appear to be significant for the numerical change in the number of individuals as 1.67 to 1.65 or changes only -0.06 and -0.05 . It differed from the Menhinick index based on the number of species changes 0.36 to 0.63 or increased consistently 0.13 . The index value of individuals number changes was only -0.06 and -0.05 (Figure 2). In other words, the Shannon index increased for the increase in the number of species for a given pattern of individuals and the increase of individuals for a given number of species. Nevertheless, The Shannon index changes in the number of species were not significant, and the increase or decrease in the number of individuals was high. The number of species was a change of three species from the data collected as 1.57 to 1.51 . The rise of the number of species in equal the number of individuals continues to decrease until 0.01 . In other, changes of one hundred from the number of individuals sampling data, the index was 1.68 to 1.33 or the change of the value index was -0.19 to -0.16 . It was similar to the Simpson index. There was no major change in terms of the number of species which was no more than 0.01 , but there was a slight change in index values with the change in the number of individuals that was -0.08 and -0.07 from the reduced and added one hundred individuals of sampling data. The Shannon index showed a higher percentage of the index value change from the number of individuals meaning that it was enough to answer the presence of individuals of dominant species (Figure 2).

\section{Assessment criteria}

The assessed species diversity indices showed varying correlation characteristics. Based on descriptive statistics, both Simpson and Shannon's indices showed negative correlation with variance, coefficient of variation, skewness, and kurtosis (Table 2). It's contradictive with the Menhinick index and Menhinick index, where Menhinick index showed correlation of $<-0.4$ with variance, coefficient of variation, skewness, and kurtosis and 
Margalef index showed correlation of $<-0.2$ with the four variables. In the correlation of the species diversity indices with the variables, the index of Simpson, and Shannon only correlated with individuals. It indicated both indices to be related to each other (Table 2). While, Menhinick and Margalef indices were correlated with the number of species. This strengthens Figure 2 that showed the different responses between the Margalef and Menhinick indices with the Shannon and Simpson index to the variables of the index. Figure 3 shows close relationship between Simpson index and Shannon index, while the Margalef index was closely related to the number of species. The Menhinick index tends to have a kinship with the Margalef index and also the number of species, even though the kinship distance was quite far.

Margalef index was the best index for mangrove community measurement. It caused the index to pass through all assessment criteria. Menhinick's index was moderate with six criteria. It was better than Simpson and Shannon indices. In this study, Manhinick was a low correlation with the number of species at the equal number of individuals, thus the index wasn't sensitive to the number of species changes. This index could not respond to the number of individuals at an equal number of species. The Simpson and Shannon indices had a similar result for assessment criteria of the best index. Both indices got one passed and eight not passed. The indices show a high correlation with sample variance and normality distribution. It made indices not responsive to equal or unequal variable tests. All indices were clustered in two similarity characteristics. Simpson and Shannon's indices clustered in indices that were responsive to individuals of the dominant species, while Margalef and Menhinick indices clustered in indices that were responsive to the number of species (Table 3).

Table 1. Descriptive statistics and species diversity indices value of sample simulation tests

\begin{tabular}{lcccccccccc}
\hline \multirow{2}{*}{ Sample } & \multicolumn{2}{c}{ Sample variance } & \multicolumn{2}{c}{ Normality marker } & \multicolumn{2}{c}{ Variable (no. of) } & \multicolumn{3}{c}{ Species diversity indices } \\
\cline { 2 - 10 } & Variance & CoefVar & Skewness & Kurtosis & Species & Individuals & Simpson (1-D) & Shannon & Menhinick & Margalef \\
\hline S & 5129.3 & 200.13 & 3.04 & 9.79 & 8 & 501 & 0.66 & 1.466 & 0.36 & 1.12 \\
S-3 & 5142.2 & 200.38 & 3.02 & 9.72 & 11 & 501 & 0.66 & 1.491 & 0.49 & 1.60 \\
S+3 & 5134.3 & 200.23 & 3.03 & 9.76 & 14 & 501 & 0.66 & 1.505 & 0.63 & 2.10 \\
N-100 & 2271 & 166.38 & 2.37 & 5.66 & 11 & 401 & 0.74 & 1.68 & 0.55 & 1.67 \\
N & 5129.3 & 200.13 & 3.04 & 9.79 & 11 & 501 & 0.66 & 1.491 & 0.49 & 1.61 \\
N+100 & 9416.1 & 226.04 & 3.33 & 11.61 & 11 & 601 & 0.59 & 1.33 & 0.44 & 1.56 \\
\hline
\end{tabular}

Table 2. Correlations between species diversity with selected descriptive statistics, variable of species diversity indices and inter-species diversity indices

\begin{tabular}{|c|c|c|c|c|c|c|c|c|c|c|}
\hline \multirow[b]{2}{*}{ Index } & \multicolumn{4}{|c|}{ Descriptive statistics } & \multicolumn{2}{|c|}{ Variable (no. of ...) } & \multicolumn{3}{|c|}{ Inter-diversity indices } & \multirow[b]{2}{*}{ Margalef } \\
\hline & Variance & CoefVar & Ske & is & ies & Individuals & $\begin{array}{c}\text { Simpson } \\
\text { (1-D) }\end{array}$ & Shannon & Menhinick & \\
\hline Simp & $-0.978 *$ & $-0998 *$ & $969^{*}$ & $960 *$ & 0.003 & $-0.999 *$ & & 0.994* & 0.381 & 0.115 \\
\hline Shannon & $-0.965^{*}$ & $-0.993 *$ & $-0.970 *$ & $-0.970 *$ & 0.110 & $-0.991 *$ & $0.994 *$ & & 0.478 & 0.221 \\
\hline Menhinick & -0.369 & -0.376 & -0.375 & -0.370 & $0.926^{*}$ & -0.377 & 0.381 & 0.478 & & $0.962 *$ \\
\hline Margalef & -0.108 & -0.110 & -0.119 & -0.114 & $0.994 *$ & -0.111 & 0.115 & 0.221 & $0.962 *$ & \\
\hline
\end{tabular}

Note: *High correlation

Table 3. Assessment criteria of the best species diversity indices

\begin{tabular}{lcccc}
\hline Assessment criteria & Simpson & Shannon & Menhinick & Margalef \\
\hline Sensitivity to the number of species at equal the number of individuals & Not Passed & Not Passed & Not Passed & Passed \\
Insensitivity to the number of individuals at equal the number of species & Not Passed & Not Passed & Not Passed & Passed \\
Low correlation with variance & Not Passed & Not Passed & Passed & Passed \\
Low correlation with coefficient of variation & Not Passed & Not Passed & Passed & Passed \\
Low correlation with skewness & Not Passed & Not Passed & Passed & Passed \\
Low correlation with kurtosis & Not Passed & Not Passed & Passed & Passed \\
High correlation with the number of species & Not Passed & Not Passed & Passed & Passed \\
Low correlation with the number of individuals & Not Passed & Not Passed & Passed & Passed \\
Good correlation with similar indices & Passed & Passed & Passed & Passed \\
& 1 Passed & 1 Passed & 7 Passed & 9 Passed \\
& Score & 8 Not Passed & 8 Not Passed 2 Not Passed 0 Not Passed \\
\hline
\end{tabular}



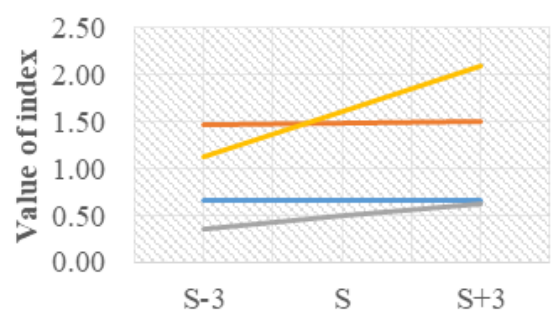

No. of Species

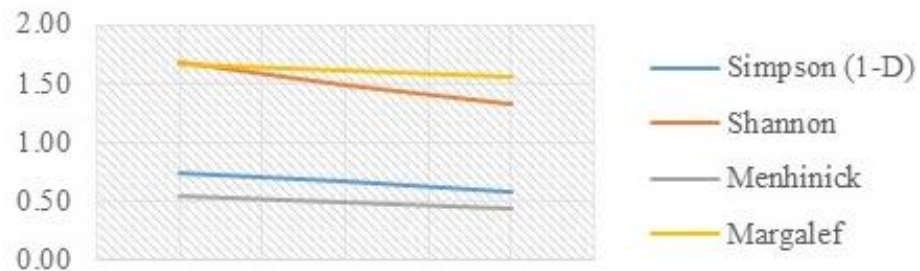

0.00

No. of Individuals

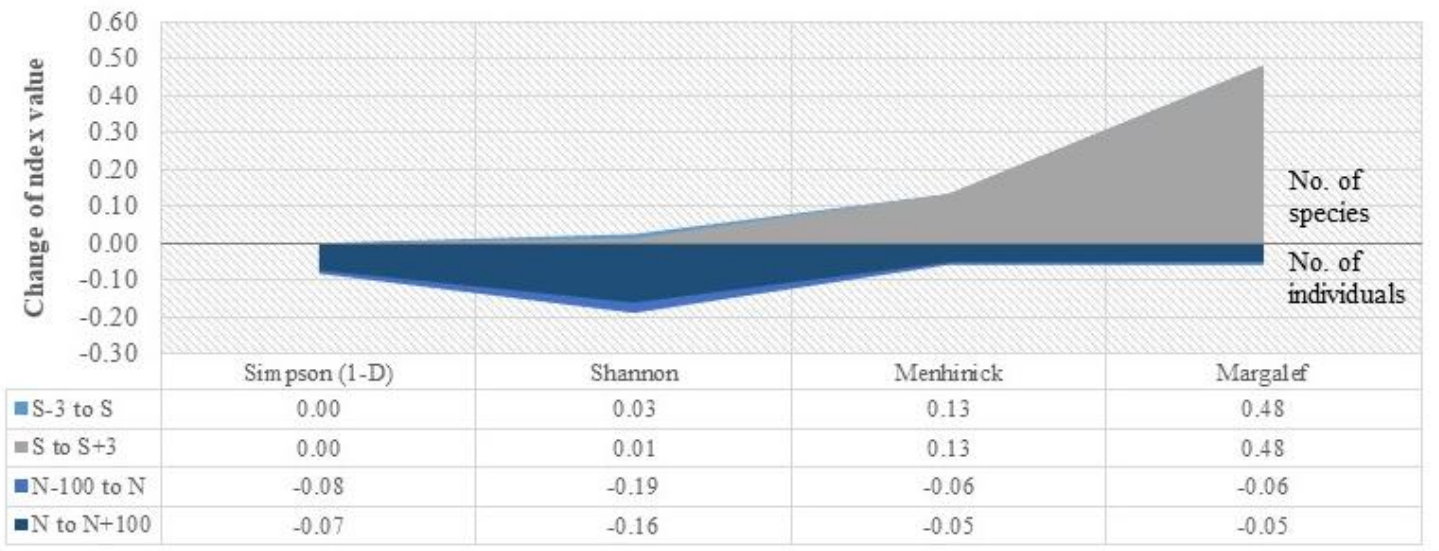

Figure 2. Result of simulation tests for species diversity indices based on mangrove community data. A. Value of index changes based on the number of species simulation, B. Value of index changes based on the number of individuals simulation, C. Amount of value changes on each diversity indices

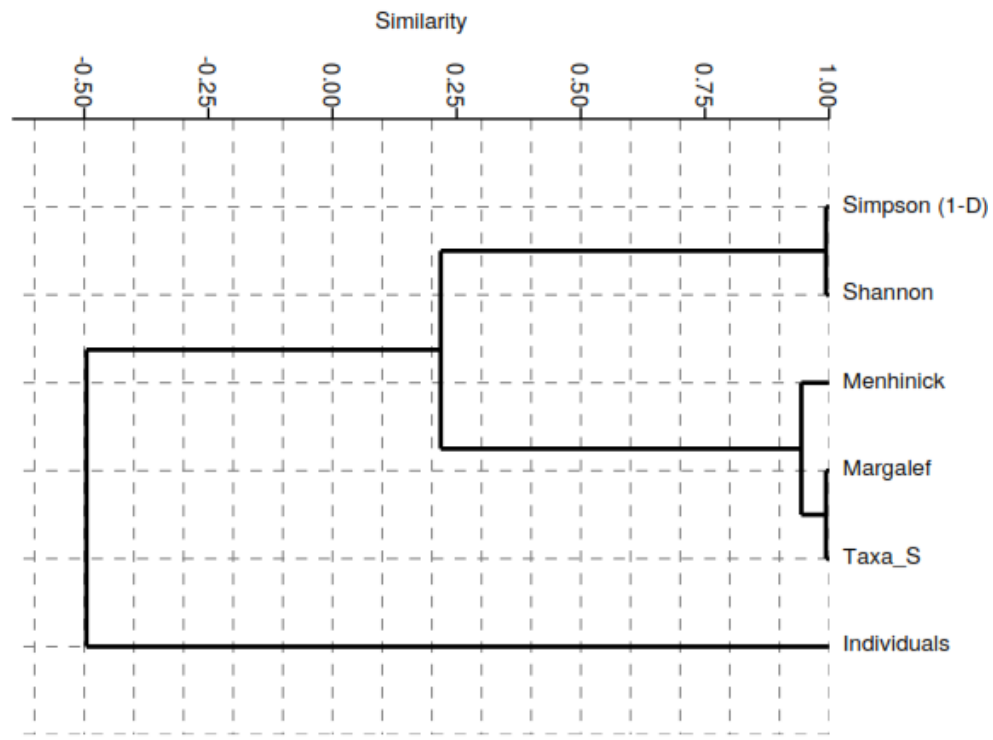

Figure 3. Cluster analysis of species diversity indices

\section{Discussion}

Non-parametric indices should not correlate to a high degree with some basic descriptive statistics characterizing data variability and normality markers (Heip and Engels 1974; Hubalek 2000). For example, increased variance sample and normality marker affected Simpson and Shannon indices significantly, but it didn't with Menhinick and Margalef Indices. Similar variance and normality marker couldn't affect Simpson and Shannon indices significantly, but they were significant to Menhinick and Margalef Indices. The species diversity indices should deviate from normal distribution as randomized individuals are sampled. According to Hopkins et al. (2018), nonparametric tests do not rely on assumptions about the shape or parameters of the underlying population distribution, and are known to be distribution-free (Orcan 2020). The use of skewness and kurtosis values to check normality is common in practice (Blanca et al. 2013). As well as the 
sample variance, standard deviation, standard error, and coefficient of variation are among the most frequently used statistics used to assess the diversity of communities (Thukral et al. 2019).

The index variability showed Simpson and Shannon's indices were relatively low, while Menhinick and Margalef Indices were high. Daly et al. (2018) suggest the variability of index value to be high but not overestimates. According to Heip and Engels (1974), the better the variability of the index, the poorer its conformity with the total population or its statistical performance with regard to normality. Nevertheless, Garcia et al. (2015) do not recommend the high variability of the index for ecoregion diversity or exceeding 50 ha sample or species with high range areas. It was overestimating and must truly consider the number of individuals.

Species diversity indices must correlate with either one of the variables or variables such as the number of species or individuals. An increase in the number of species is followed by an increase in the number of individuals, while an increasing number of species may not always follow an increase in the number of individuals. The number of species and individuals are fundamentally bonded to each other (Morris et al. 2014). The diversity of communities varies between those with an equal number of species with an unequal abundance of individuals and those with equal individual abundance but an unequal number of species. This confirms that species diversity measures have varying values caused by the number of species and individuals. Thus, a characteristic community like a mangrove community may get different values of the index, which must be defined conceptually and statistically (Daly et al. 2018). Four species diversity resulted in different values and that correlate to their index variables characteristics such as Margalef and Menhinick indices correlated to the number of species while Simpson and Shannon indices to the number of individuals. Mangrove communities can only grow, develop, and survive in the latitudinal range of tidal areas (Istomo et al. 2020) with limited species diversity and relatively clumped. Thus, the Margalef index was suitable for the mangrove community as conceptually and statistically, it could accommodate limited species and reduce the clumping of individuals.

Based on the simulation test result, we knew the four indices had different characteristics. Simpson and Shannon's indices were responsive to the number of individuals changes, while the Menhinick and Margalef ones to the number of species changes. Meaning that heterogeneity corresponds to the number of individuals and species richness corresponds to the number of species Magurran (2004). Hubalek (2000) further asserted that the Simpson index is a measure of dominance that gives weightage to dominant species, Shannon index gives weightage to dominant and rare species, while Margalef and Menhinick index gives weightage to the number of species. In this study, increase and decrease of the number of rare species didn't make Simpson and Shannon change significantly, but increase and decrease of the individuals of dominant species made it significant. It's true to argue that dominant species influence the Simpson index and the chances of species similarity in a community so high dominance or chances of two individuals in the same species indicate low species diversity Simpson (1949). The same arguments by Daly et al. (2018) indicated that the Shannon index is insensitive to rare species and highly biased on a small sample size (Konopiński 2020). It is reliable in measuring species abundance with individual distribution dominated by common species (Magurran 2004). Shannon index measures the average degree of uncertainty in predicting where individual species chosen at random will belong, so the increase in value of individuals among the species becomes even (Kim et al. 2017). However, in some studies, the Shannon index showed less consistency (Garcia et al. 2015) for being sensitive to rare or dominant species or neither of them (Magurran 2004; Moris et al. 2014; Daly et al. 2018; Konopinski 2021). It is important because the mangrove community has major and minor mangrove species that would be affected by abundance-based criteria such as dominance and rarity. However, Margalef and Menhinick indices do not truly consider those criteria (Magurran 2004).

Margalef and Menhinick indices were based on the distribution of individuals which have a definite conformity relationship between the total number of species and the total number of individuals like geometric progression rule (Margalef 1958; Menhinick 1964). In this study, indices' responses to the variables of the index showed it. The change in the value of the Margalef index was higher than the Menhinick index value, as stated by Margalef (1958) and Magurran (2004). The Menhinick index was underestimated, as may be indicated by the rise of rare species which had a small number of individuals. Although the Menhinick index is unbiased to sample size (Tinio and Sebual 2021), the index to low responsive to rare species. That was contradictive with Margalef that had high value caused by the number of species. According to Magurran (2004) and Goudarzian and Erfanifard (2017), that is namely biased toward rare species. in this study, the bias of the Margalef index was the identity of mangrove species that have a small number of species. It should be sensitive. Nevertheless, the value of the Menhinick and Margalef indices are not affected by low or high abundance and what mattered was just how many species were there in those diversity indices formulas(Magurran 2004),

The characteristics response for the variables made the species diversity clustered with similar indices. The result was quite different from Kumar et al. (2017) in which the four species diversity indices are in good consonance with each other. But this result was the same as that of Jintun (1999) who stated that Shannon and Simpson's indices have a good inter-relationship but not with Menhinick and Margalef indices, although the two wealth indices are strongly interconnected (Mirzaie et al. 2013). According to Menhinick (1964), the Menhinick index is a result of the division of the total number of species with the reduction of the total individual using a square root. The square root has a lower variation, thus the index value is not easily changed suddenly. The problem this index looked at was the small number of species in this case. It made the Menhinick 
index unchanged significantly and difficult to interpret. Kanieski et al. (2018) stated that the Margalef index obtained is influenced by the sample size taken, while the Menhinick index was not significantly affected by the sample size. In line with opinion of Magurran (2004) who stated that there is a sign of the influence of sample size on Margalef index values, although Margalef (1958) justified its index to be free from the influence of sample size, while Menhinick didn't (Magurran 2004).

Different indices indeed allow quantifying different facets, mainly species number, evenness, or more complex variations considering taxonomic, phylogenetic, and/or functional differences between species (Meynard et al. 2011; Pavoine 2012; Granger et al. 2015). Menhinick, Shannon, and Simpson (1-D) indices are good bird and copepod taxa measures in various communities or locations (Heip and Engels 1974; Hubalek 2000; Goudarzian and Evanirfad 2017; Konopiński 2020; Tinio and Sebual 2021). Even According to Garcia et al. (2015), the Simpson Index (1-D) is the most useful to define which regions have a greater diversity of ecosystems compared to them. Thus, current study results didn't mean that the Menhinick, Shannon, and Simpson (1-D) indices were a poor measure but they were good in terms of their respective strengths based on taxa or ecological characteristics of the communities.

In conclusion from the present study, Margalef index was found to be the best index for species diversity measurement in the mangrove community rather than Shannon, Simpson, and Menhinick indices. The index showed low correlation with sample variance and normality markers as the identity of non-parametric statistics. In the variables of an index, the Margalef index had a good correlation with the number of species, but there it was not correlated with the number of individuals. It was evidenced with the index that is sensitive to the number of species at the equal number of individuals but insensitive to the number of individuals at the same number of species. It was suitable with species of mangrove community which had limited number of species but had many clumped individuals. The index also correlates with a similar index such as the Menhinick index. Thus, we recommend the Margalef index for measuring the species diversity of the mangrove community. It can be used for the monitoring and evaluation of the biodiversity assessment for the mangrove community. The assessment should not be using several indices that have a similar meaning, ecologists called species richness and heterogeneity. Those indices mean higher value of indices indicated the high species diversity too. Nevertheless, some ecologists recommend combining it with evenness as a typical abundance that can reflect aspects of diversity in a community. Both of them had an inconsistent relationship (Su 2018), even not correlated (Soininen 2012).

\section{ACKNOWLEDGEMENTS}

We express our deepest gratitude to Arif Susanto S. Hut and Ashar Ridhovan SP. who were very helpful during field data collection. It is also inseparable from the Estuary Foundation, a partner in collaboration and research support on coastal environmental conservation, including the mangrove community.

\section{REFERENCES}

Blanca MJ, Arnau J, Lopez-Montiel D, Bono R, Bendayan R. 2013. Skewness and kurtosis in real data samples. Methodology 9 (2): 7884. DOI: $10.1027 / 1614-2241 / \mathrm{a} 000057$.

Chiarucci A, Bacaro G, Scheiner S. 2011. Old and new challenges in using species diversity for assessing biodiversity. Phil Trans R Soc B 366: 2426-2437. DOI: 10.1098/rstb.2011.0065.

Daly AJ, Baetens JM, Baets BD. 2018. Ecological Diversity: Measuring the Unmeasurable. Mathematics 6: 119. DOI: 10.3390/math6070119.

Evangelista HBA, Thomaz SM, Evangelista LR. 2012. Comparison of Diversity Indices Applied to Macrophyte Incidence-Based Data. Braz Arch Biol Technol 55 (2): 277-282. DOI: 10.1590/S151689132012000200014

García LMC, Arreola-Lizarraga JA, Mendoza-Salgado RA, GalinaTessaro P, Beltran-Morales LF, Ortega-Rubio A. 2015. Applying ecological diversity indices with ecosystem approach at ecoregional level and prioritizing the decree of new protected natural areas. Interciencia 40 (3): 179-184.

Goudarzian P, Erfanifard SY. 2017. The efficiency of indices of richness, evenness and biodiversity in the investigation of species diversity changes (case study: migratory water birds of Parishan international wetland, Fars province, Iran). Biodiv Intl J 1 (2): 41-45. DOI: 10.15406/bij.2017.01.00007.

Granger V, Bez N, Fromentin JM, Meynard C, Jadaud A, Merigot B. 2015. Mapping diversity indices: not a trivial issue. Methods Ecol Evol 6: 688-696. DOI: 10.1111/2041-210X.12357.

Heip C, Engels P. 1974. Comparing species diversity and evenness indices. J Mar Biol Ass 54: 559-563. DOI: 10.1017/S0025315400022748.

Hopkins S, Dettori JR, Chapman JR. 2018. Parametric and non-parametric tests in spine research: why do they matter?. Glob Spine J 8 (6): 652 654. DOI: $10.1177 / 2192568218782679$.

Hubalek Z. 2000. Measures of species diversity in ecology: an evaluation. Folia Zool 49 (4): 241-260.

Istomo, Kusmana C, Dwiyanti FG, Malik D. 2020. Comparison of several methods of stands inventory prior to logging towards the yield volume of mangrove forest in Bintuni Bay, West Papua Province, Indonesia. Biodiversitas 21 (4): 1438-1447. DOI: 10.13057/biodiv/d210423.

Jintun CTZ. 1999. A comparison of fifteen species diversity indices. J Heinan Sci 17: 55-57. DOI: 10.13537/j.issn.1004-3918.1999.s1.018 [Chinese]

Kanieski MR, Longhi SJ, Soares PRC. 2018. Methods for Biodiversity Assessment: Case Study in an Area of Atlantic Forest in Southern Brazil. intechopen, UK. DOI: 10.5772/intechopen.71824.

Kim BR, Shin J, Guevarra R, Lee JH, Kim DW, Seol KH, et al. 2017. Deciphering diversity indices for a better understanding of microbial communities. J Microbiol Biotechnol 27 (12): 2089-2093. DOI: 10.4014/jmb.1709.09027.

Konopiński MK. 2020. Shannon diversity index: a call to replace the original Shannon's formula with unbiased estimator in the population genetics studies. Peer J 8: e9391. DOI: 10.7717/peerj.9391.

Kumar V, Sharma A, Bhardwaj R, Thukral AK. 2017. Phytosociology and Landsat TM data: A case study from river Beas bed, Punjab, India. In: 38th Asian Conference on Remote Sensing (ACRS), 23-27 October 2017.

Kumar V, Thukral AK, Sharma A, Bhardwaj R. 2021. Extending the concept of entropy-negentropy for the assessment of ecological dominance and diversity at alpha, beta and gamma levels. Geol Ecol Landsc 1-13. DOI: 10.1080/24749508.2021.1923270.

Magurran AE. 2004. Measuring Biological Diversity. Blackwell Scientific Oxford, UK.

Margalef R. 1958. Information theory in ecology. Gen Syst 3: 36-71

Meynard CN, Devictor V, Mouillot D, Thuiller W, Jiguet F, Mouquet N. 2011. Beyond taxonomic diversity patterns: how do $\alpha, \beta$ and $\gamma$ components of bird functional and phylogenetic diversity respond to 
environmental gradients across France?. Global Ecol Biogeogr 20: 893-903. DOI: $10.1111 /$ j.1466-8238.2010.00647.x.

Menhinick EF. 1964. A comparison of some species-individuals diversity indices applied to samples of field insects. Ecol 45: 859-861. DOI $10.2307 / 1934933$

Mirzaie FS, Ghorbani R, Montajami S. 2013. A Comparative Study of Different Biological Indices Sensitivity: A Case Study of Macroinvertebrates of Gomishan Wetland, Iran. World J Fish Mar Sci 5 (6): 611-615. DOI: 10.5829/idosi.wjfms.2013.05.06.74225.

Morris EK, Caruso T, Buscot F, Fisher M, Hancock C, Maier TS et al. 2014. Choosing and using diversity indices: insights for ecological applications from the German Biodiversity Exploratories. Ecol Evol 4 (18): 3514-3524. DOI: $10.1002 /$ ece3.1155.

Nfotabong-Atheull A, Din N, Dahdouh-Guebas F. 2013. Qualitative and quantitative characterization of mangrove vegetation structure and dynamics in a Peri-urban setting of Douala (Cameroon): An approach using Air-Borne Imagery. Estuar Coast 36: 1181-1192. DOI: 10.1007/s 12237-013-9638-8

Orcan F. 2020. Parametric or Non-parametric: Skewness to test normality for mean comparison. Intl J Ass Tools Edu 7 (2): 255-265. DOI 10.21449/ijate.656077.

Pandita S, Kumar V, Dutt HC. 2019. Environmental variables vis-à-vis distribution of herbaceous tracheophytes on northern sub-slopes in Western Himalayan ecotone. Ecol Process 8 (45): 1-9. DOI 10.1186/s13717-019-0200-x.

Palaghianu C. 2014. A tool for computing diversity and consideration on differences between diversity indices. J Lands Manag 5 (2): 78-81.
Pavoine S. 2012. Clarifying and developing analyses of biodiversity: towards a generalization of current approaches. Methods Ecol Evol 3: 509-518. DOI: 0.1111/j.2041-210X.2011.00181.x.

Semeniuk V, Cresswell ID. 2013. A proposed revision of diversity measures. Diversity 5: 613-626. DOI: 10.3390/d5030613.

Shah JA, Pandit AK. 2013. Application of diversity indices to crustacean community of Wular Lake, Kashmir Himalaya. Intl J Biodiv Conserv 5 (6): 311-316. DOI: 10.5897/IJBC2013.0567.

Shannon CE, Weaver W. 1949. The Mathematical Theory of Communication. Illinois University Press, Urbana, IL.

Simpson EH. 1949. Measurement of Diversity. Nature 163: 688. DOI: 10.1038/163688a0.

Soininen J, Passy S, Hillebrand H. 2012. The relationship between species richness and evenness: a meta-analysis of studies across aquatic ecosystems Oecologia 169: 803-809. DOI: 10.1007/s00442-0112236-1.

Su Qiang. 2018. A relationship between species richness and evenness that depends on specific relative abundance distribution. Peer $\mathrm{J} 6$ : e4951. DOI; 10.7717/peerj.4951.

Thukral AK, Bhardwaj R, Kumar V, Sharma A. 2019. New indices regarding the dominance and diversity of communities, derived from sample variance and standard deviation. Heliyon 5: e02606. DOI: 10.1016/j.heliyon.2019.e02606.

Tinio JNG, Sebual CJ. 2021. On the Efficiency of Some Alpha Diversity Indices: A Simulation Study Using Bootstrap Resampling. J Wildl Biodiv 5 (1): 32-39. DOI: 10.22120/jwb.2020.127654.1142.

Yeom DJ, Kim JH. 2011. Comparative evaluation of species diversity indices in the natural deciduous forest of Mt. Jeombong. J For Sci Tech 7 (2): 68-74. DOI: 10.1080/21580103.2011.573940. 